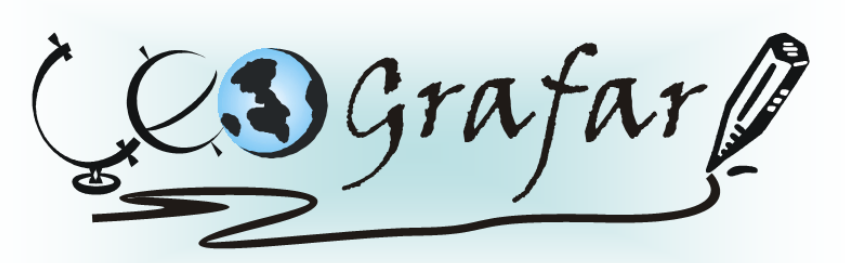

Revista Eletrônica do Programa de Pós-Graduação em Geografia - UFPR

\title{
O BAIRRO BELVEDERE COMO COMPARTIMENTO DA PAISAGEM DE BELO HORIZONTE: PROPOSTA DE UMA VISÃO INTEGRADA ${ }^{1}$
}

\author{
THIAGO ANDRADE DOS SANTOS ${ }^{2}$ \\ AMANDA AZEVEDO DE ANDRADE ${ }^{3}$ \\ CAMILA PETTERSEN ${ }^{4}$ \\ HEBERT COSTA CARVALHO ${ }^{5}$ \\ FÁBIO FRANCISCO MAIA ${ }^{6}$
}

\begin{abstract}
RESUMO
Este estudo tem como objetivo a análise do bairro Belvedere como uma paisagem homogeneizável dentro de Belo Horizonte - MG e a identificação das geofácies que compõem essa paisagem. A metodologia utilizada é a proposta por Bertrand (2007), o sistema GTP que possibilita ao pesquisador o estudo das distintas temporalidades e dinâmicas que influem diretamente na configuração da paisagem. O bairro Belvedere é dividido em I, II e III e localiza-se na região centro-sul de Belo Horizonte. Composto por filitos e quartzitos, além do relevo escarpado, possui temperaturas amenas, o que o torna um local estratégico e uma barreira natural em relação aos outros bairros. O Belvedere I e II são compostos por mansões tradicionais construídas na década de 1950. O Belvedere III possui prédios luxuosos construídos a partir do ano 2000. No Belvedere, as interações entre os diferentes elementos componentes da paisagem (meio físico e sócio-cultural) fazem deste um local muito atrativo à obtenção de lucros pelo setor imobiliário, mas isso tem provocado impactos ambientais e sociais à cidade. Dessa forma, este estudo promove uma análise integrada sobre os elementos componentes do meio físico e do meio sóciocultural do Belvedere utilizando a metodologia do sistema GTP, articulando as diferentes territorialidades e temporalidades presentes na construção da
\end{abstract}

\footnotetext{
${ }^{1}$ Este trabalho foi concebido como requisito fundamental para a conclusão da disciplina "Estudo de paisagem em geografia" ministrada pela prof. $\operatorname{Dr}(a)$. Janise Bruno Dias no segundo semestre de 2010, na Universidade Federal de Minas Gerais. Todo o trabalho foi revisado e recebeu os valiosos conselhos da prof. $\operatorname{Dr}(\mathrm{a})$ Janise Bruno Dias.

${ }^{2}$ Graduado em Geografia (UFMG) - E-mail: thiago andsant@yahoo.com.br

${ }^{3}$ Graduada em Geografia (UFMG) - E-mail: amandageo@ufmg.br

${ }^{4}$ Graduada em Geografia (UFMG) - E-mail: camilapett@hotmail.com

${ }^{5}$ Graduado em Geografia (UFMG) - E-mail: herbertcostacarvalho@hotmail.com

${ }^{6}$ Graduado em Geografia (UFMG) - E-mail: phabynhomaia@yahoo.com.br
} 
paisagem local, tornando-a distinta de seu entorno e também, identificando diferenciações dentro dos seus próprios limites. A utilização da paisagem como categoria de estudo se justifica pela necessidade de uma análise integrada entre o meio físico e sócio-cultural que possa ser utilizada para a prevenção e ou minimização de impactos ambientais além do planejamento e gestão territorial do espaço. Para esse fim, a metodologia proposta por Bertrand traz a possibilidade de reflexões e análises que contemplam esse tipo de abordagem, as quais poderão subsidiar políticas públicas de planejamento e gestão territorial no município.

Palavras-Chave: Sistema GTP, Território, Paisagem, geofácies

\title{
THE BELVEDERE NEIGHBORHOOD AS A COMPARTMENT OF BELO HORIZONTE'S LANDSCAPE: PROPOSAL FOR AN INTEGRATED VIEW
}

\begin{abstract}
This study aims to analyze the Belvedere neighborhood as a distinct landscape , in Belo Horizonte-MG, and the identification of its geofacies that compose this landscape. The methodology used is the proposed by Bertrand (2007), the GTP system, that allows the researcher the study of the different temporalities and dynamics that influence the configuration of the landscape. The area is divided in Belvedere I, II and III and is located in south-central region of Belo Horizonte. Formed by lithology of phyllites and quartzites, and the steep topography this place generates soft temperatures, which makes it a strategic location and a natural barrier in relation to other neighborhoods. Belvedere I and II are composed by a traditional mansions built in the 1950 decade. The Belvedere III boasts luxurious buildings constructed after 2000. In the Belvedere, the interactions between different elements of landscape's components (physical and territorial) make it a very attractive place to make profits by capitalists companies, but this has caused environmental and social impacts to the city. Thus, this study promotes an integrated analysis of the component elements of the physical and territorial environment using the methodology proposed by Bertrand GTP (2007), articulating the territorial and temporal differences in the construction of the local landscape, making it distinct from its surroundings and also by identifying differences within their own limits. The use of landscape category in this study is justified by the needs for an integrated analysis that could be used to prevent and or minimize environmental impacts through the territorial planning and management of space. In the end, we proved that the methodology proposed by Bertrand brings the possibility of reflection and analysis that contemplate this type of approach, which can support public policies, management, and planning of the municipality.
\end{abstract}

Key words: GTP system, territory, landscape, geofaces 


\section{INTRODUÇÃO}

O bairro Belvedere está localizado ao sul da região centro-sul de Belo Horizonte e, ao longo das últimas duas décadas, vem passando por um processo interessante em relação ao uso e ocupação do solo, cujos embates entre os interesses do setor imobiliário, a legislação urbano-ambiental e a população são marcantes. Esse processo adquiriu um maior destaque na paisagem da capital mineira após a construção do Belvedere III. O bairro é dividido em Belvedere I, II e III e comporta uma população de alta renda em um dos locais mais valorizados da cidade e, por isso, é amplamente apropriado pelo setor imobiliário. Os dois primeiros (I e II) são compostos por mansões construídas a partir da década de 1950, enquanto o III é composto por prédios luxuosos construídos a partir de 2000. Entretanto, a ocupação do Belvedere III somente pode ser feita mediante uma alteração da legislação urbanística existente, após a promulgação da constituição federal de 1988, cujas premissas deram maior autonomia aos municípios na gestão dos seus territórios.

No Belvedere, as interações entre os diferentes elementos componentes da paisagem (meio físico e sócio-cultural) fazem deste um local muito atrativo à obtenção de lucros pelo setor imobiliário, mas, por outro lado, isso tem provocado conflitos e impactos ambientais e sociais em Belo Horizonte. $\mathrm{O}$ bairro Belvedere está localizado em um elevado patamar da Serra do Curral, possuindo uma litologia composta por quartzitos e filitos, limitados, a oeste e a leste, pela escarpa da serra do curral e ao norte pela depressão belohorizontina. As áreas do bairro possuem declividades que variam de suaves à levemente onduladas. A privilegiada localização e essa constituição natural de sua paisagem, isola o bairro do restante da cidade e o torna detentor de amenas temperaturas e de uma vista privilegiada para toda cidade de Belo Horizonte. Dessa forma, o Belvedere destaca-se do seu entorno e surge como uma distinta unidade da paisagem de Belo Horizonte. Em um contexto, no qual o alto grau de antropização da superfície do planeta e o desrespeito à dinâmica da natureza têm gerado muitos problemas ambientais, um estudo como este pode ser muito importante para que se possa 
pensar em métodos de análise mais integrados que possam romper com 0 dualismo verificado nas análises geográficas.

Dessa forma, este estudo promove uma análise integrada sobre os elementos componentes do meio físico e do meio sócio-cultural do Belvedere, região sul de Belo Horizonte, utilizando a metodologia do sistema GTP (Geossistema, território, paisagem) proposta por Bertrand (2007), articulando as diferentes territorialidades e temporalidades presentes na construção da paisagem local, tornando-a distinta de seu entorno e também, identificando diferenciações (geofácies) dentro dos seus próprios limites. A utilização da "paisagem" como categoria de análise deste estudo se justifica pela necessidade de uma análise integrada entre o meio físico e sócio-cultural, que possa ser utilizada para a prevenção e ou minimização de impactos ambientais, além de auxiliar o planejamento e a gestão territorial do espaço. Para esse fim, a metodologia proposta por Bertrand (sistema GTP) traz a possibilidade de reflexões e análises que contemplam esse tipo de abordagem, as quais poderão subsidiar políticas públicas de planejamento e gestão territorial no município.

\section{ASPECTOS CONCEITUAIS E METODOLÓGICOS: O GEOSSISTEMA, O TERRITÓRIO E A PAISAGEM NA COMPOSIÇÃO DO SISTEMA GTP}

Para Bertrand C. e Bertrand G. (2007, p. 294-295), o sistema GTP promove a reaproximação de três conceitos ou noções (Geossistema, território e paisagem) com o intuito de analisar o funcionamento de determinado meio ambiente geográfico na sua globalidade, porém, segundo o autor, esse método não esgota a totalidade de nenhum desses conceitos. Nesse sentido, o sistema GTP é utilizado para demonstrar a diversidade, interatividade $\mathrm{e}$ interdisciplinaridade do meio ambiente geográfico, tentando romper com a dicotomia existente nas análises ambientais, em que de um lado se colocam as ciências da natureza e do outro as ciências da sociedade.

De acordo com Bertrand, C. e Bertrand G. (2007), no sistema GTP, o estudo do meio ambiente torna-se inviável quando se busca apreendê-lo a partir de um único conceito ou método. Para esses autores é necessário, "tratar o meio ambiente a partir de um sistema conceitual tripolar e interativo: geossistema, 
território e paisagem. Resumindo, uma estratégia tridimensional, em três espaços e três tempos". (BERTRAND, C. \& BERTRAND, G. 2007)

Dentro da proposta de utilização do sistema GTP, procura-se fazer um estudo que nos possibilitasse a compreensão da paisagem por sua característica tripolar (geossistema, território e paisagem), numa perspectiva temporal do sistema em questão.

O Geossistema permite a análise da estrutura e do funcionamento biofísico de um espaço geográfico tal como ele funciona atualmente, ou seja, com um grau de antropização. O território permitirá analisar as repercussões da organização e dos funcionamentos sociais e econômicos sobre o espaço considerado. A paisagem, por sua vez, irá representar a dimensão sociocultural (BERTRAND, C. \& BERTRAND, G. 2007, P. 294).

A primeira das três frentes metodológicas utilizadas no presente estudo, 0 método geossistêmico, componente do sistema GTP (BERTRAND, 2007), consiste no levantamento de dados para compor os mapas altimétrico, geológico e de declividade, além da elaboração de um transecto que permite a contextualização do local analisado. O geossistema é uma dimensão do espaço terrestre onde os diversos componentes naturais estão conectados de forma sistêmica uns com os outros e apresentam uma integridade definida, interagindo com a esfera cósmica e com a sociedade humana. (SOCHAVA 1978, p. 292). Essa primeira frente metodológica constitui a base material da análise paisagística, mas sozinha não é capaz de explicar a configuração atual da paisagem estudada seguindo as premissas do método proposto.

Posteriormente, a segunda frente metodológica se dá em torno dos atores sociais ou agentes transformadores da paisagem, portanto, foram observadas informações acerca do cenário político e econômico de Belo Horizonte e das características socioeconômicas dos moradores do bairro Belvedere. Entende-se que os atores sociais configuram o território em função de seus projetos paisagísticos, de sua percepção e, sobretudo, de sua cultura.

O conceito de território trabalhado neste estudo é o de Haesbaert (2002, pág. 22 e 23), em que o autor entende o território como algo mais complexo que apenas a questão dos estados nação ou simples polígonos, porções do espaço geográfico que foram delimitadas e não permitem sobreposições. Para este autor 
os territórios são "construtores de identidades" e em sua complexidade se inserem a identificação cultural e diversos símbolos que levam a um sentido de pertencimento a esse território. Souza (1995) citado por Haesbaert (2002, p. 26), prossegue dizendo que o território é um campo de forças, as relações de poder espacialmente delimitadas e operando, destarte, sobre o substrato referencial. Haesbaert (2002, p. 26), completa afirmando que o exercício do poder pode depender muito diretamente da organização espacial, das formas espaciais, mas aí falando dos trunfos de defesa do território e não do conceito em si. Santos (2001) assim como Haesbaert (2002), entende que o território não é apenas o substrato das relações sociais, mas, expressa uma identidade, que implica o pertencimento a uma determinada porção do espaço. Nessa visão, o território emerge com a base das relações de troca, do trabalho, da moradia, e diversos outros aspectos. Santos (1994, p. 15), infere que é o uso do território que faz dele o objetivo da análise social e não o território em si.

Por fim, na terceira frente metodológica, o bairro é identificado pela ótica da paisagem e, a partir desse ponto, foram delimitadas geofácies, que emergem como o resultado das interações entre as dinâmicas e as temporalidades do geossistema e do território, que juntos são os principais formadores dessa paisagem. Sauer entende a paisagem como um organismo complexo, feito de uma associação específica de formas e apreendido pela análise morfológica e esta paisagem somente pode ser natural e cultural. Seu conteúdo é constituído pela combinação de elementos materiais e de recursos naturais, disponíveis no lugar, com as obras humanas correspondentes ao uso que fizeram os grupos culturais que ali viveram. (ROUGERIE; BEROUTCHACHVILI, 1991, p. 30-31)

Dias (2006, p. 121), infere considerando que a ação do homem imprime nas paisagens o resultado de sucessivas combinações de sociedades sobre 0 espaço e a relação estabelecida entre ambos. Nesse contexto, a geofácie demonstra uma fase do geossistema numa escala de maior detalhe, aquela de quilômetros quadrados, que permite uma análise mais detalhada.

Dias (2006, p. 121) cita as diretrizes metodológicas propostas por Bertrand: a delimitação das unidades (no caso dos geofácies) não deve ser um fim em si mesmo, mas uma aproximação com a realidade que busca as descontinuidades objetivas da paisagem. A delimitação deve ser tal qual se apresenta, sem 
estabelecer síntese "média" de superposição dos elementos. Deve-se talhá-la tal como paisagem global considerando os limites da dinâmica paisagística, tanto espaciais quanto temporais. A referência escalar deve permitir situá-la na dupla perspectiva do tempo e do espaço (DIAS, 2006, p. 121).

\section{RESULTADOS E DISCUSSÕES}

\subsection{A TEMPORALIDADE DO GEOSSISTEMA: CARACTERÍSTICAS FÍSICAS DO BAIRRO BELVEDERE}

O Belvedere está localizado ao pé da escarpa da Serra do Curral, em Belo Horizonte, sobre uma litologia composta por filitos do supergrupo Cercadinho e quartzitos da formação Sabará. A geomorfologia do bairro Belvedere é marcada por um relevo predominantemente escarpado nas bordas e suave no seu interior.

A figura 1 mostra que o Belvedere possui as maiores cotas altimétricas de Belo Horizonte, portanto, possui um clima mais ameno que o restante da cidade. Contudo, a alta declividade e a sua localização privilegiada (ao pé da escarpa da Serra) permite que o Belvedere mantenha certo isolamento geográfico em relação aos bairros vizinhos mais pobres.

O bairro se situa na borda da depressão belorizontina, mais precisamente no flanco leste da Serra do Curral. Essa região, por se encontrar em uma das áreas de maior altitude (de 1000 a 1200 metros), se comparada ao restante do município, possui menor pressão atmosférica, o que permite um deslocamento dos ventos locais em direção ao bairro, proporcionando temperaturas mais amenas, além de uma vista privilegiada da cidade. $O$ bairro está situado na região de maior concentração de mananciais e aquíferos da RMBH. Nos aquíferos, o solo apresenta constituição porosa, saturando no manto de decomposição, e seu manto de intemperismo pode chegar a 50 metros (normalmente oscila entre $30 \mathrm{e}$ 50). Com isso, os lençóis freáticos são muito superficiais e, portanto, muito sensíveis a poluição urbana. 


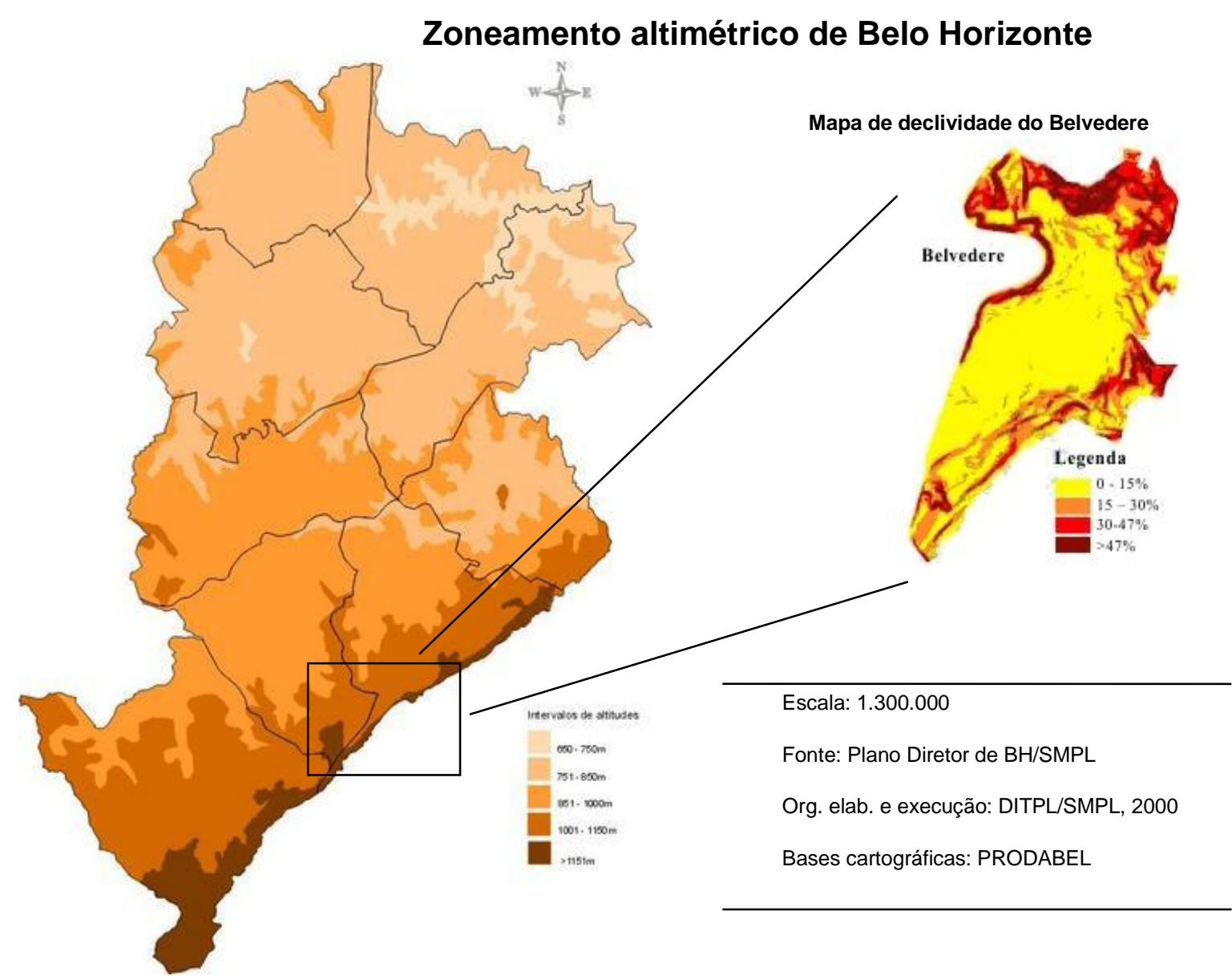

FIGURA 1 - ZONEAMENTO ALTIMÉTRICO DE BELO HORIZONTE - MG E MAPA DE DECLIVIDADE DO BELVEDERE.

FONTE: PLANO DIRETOR DE BELO HORIZONTE/SMPL E KUX et al. (2007) ADAPTADO.

Os mananciais supracitados compõem a sub-bacia do cercadinho que alimenta o Ribeirão arruda, contribuinte do Rio das Velhas, que integra uma das mais importantes bacias de Minas Gerais, a bacia do Rio São Francisco. A transição entre o cerrado e a mata atlântica é a característica vegetacional marcante na região, constituindo-se de árvores relativamente baixas (até vinte metros) e de médio porte, esparsas, disseminadas em meio a arbustos, subarbustos e uma vegetação baixa constituída, em geral, por gramíneas. As Rochas pertencem a sequência metassedimentar, na transição do grupo Sabará com o grupo Cercadinho. As rochas mais comuns nessa localidade são os xistos, filitos, quartzitos itabiritos e dolomitos. 


\subsection{ATEMPORALIDADE DO TERRITÓRIO: CARACTERIZAÇÃO SOCIOECONÔMICA E HISTÓRICA DO BELVEDERE}

O Belvedere é um bairro de Belo Horizonte que pode ser dividido em duas partes. A primeira possui mansões que abrigam os moradores mais antigos do bairro e a segunda parte (Belvedere III) é composta por prédios extremamente luxuosos construídos após a promulgação da constituição federal de 1988, na qual os municípios começaram a possuir autonomia para alterar a legislação urbana e ambiental vigentes em seu território. O Belvedere III é uma área extremamente verticalizada localizada na Serra do Curral, divisa entre a zona sul da cidade de Belo Horizonte e o município de Nova Lima. O local possui uma vista privilegiada para o restante da cidade de Belo Horizonte pelo fato de estar localizado sobre rochas quartzíticas que foram menos erodidas que os granitosguinaisses do restante da cidade. O Belvedere é habitado por uma população extremamente rica, que reside nos prédios mais luxuosos da cidade. Na região está localizado o BH Shopping, o maior shopping da cidade e, também, outros estabelecimentos que oferecem os serviços mais avançados do mercado. A proximidade com o bairro Savassi, o centro da capital e os condomínios de luxo localizados em Brumadinho e Nova Lima, garante ao local ainda maior valorização fundiária, refletindo diretamente no preço dos imóveis e do preço da terra.

Segundo Hilgert et al (2004), a verticalização correspondente ao Belvedere III se deu de forma abrupta, e só foi possível pela mudança na legislação de zoneamento da área, feita pelo, então, prefeito Sérgio Ferrara, em 1988. A partir disso, foi iniciada uma intensa polêmica envolvendo prefeitura, interesses imobiliários e a sociedade civil. A mesma autora (2004) afirma que:

Por estar situado próximo a uma área de interesse ambiental (preservação das nascentes e da biodiversidade contíguas à Mata do Jambreiro) e paisagístico (preservação da vista para Serra do Curral, patrimônio tombado por lei), era área de intensa especulação imobiliária na década de 1980. Sua localização privilegiada e a legislação de uso e ocupação do solo restritiva eram ponto de conflito entre interesses públicos e privados (HILGERT et al, 2004). 
No ano de 1976, a prefeitura de Belo Horizonte aprova a Lei de Uso e Ocupação do Solo (LUOS) que restringia a ocupação e o adensamento da área correspondente ao Belvedere para a preservação ambiental e paisagística. No ano de 1985, é sancionada a Lei no 4.034/85, que trazia uma revisão da LUOS. Essa revisão tinha como objetivo flexibilizar a LUOS para viabilizar o desenvolvimento de atividades econômicas e a geração de empregos. Segundo Rodrigues (2000, p. 9), a aprovação do empreendimento Belvedere III permitiu uma expansão da malha urbana em desconformidade com o planejamento urbano da cidade, ao "ignorar" a legislação urbanística, as avaliações de impacto ambiental, a vontade popular e os estudos oficiais.

Segundo RODRIGUES (2000, p. 13), em março de 1997, havia no bairro 30 construtoras atuando e 55 empreendimentos programados, com projetos já aprovados. Em junho de 2000, a situação do Belvedere era de 29 prédios prontos como outros 44 em construção. A expectativa era de que a conclusão dos primeiros prédios deveria gerar negócios da ordem de $\mathrm{R} \$ 350$ milhões. O preço dos imóveis do Belvedere é, em média, quase duas vezes maior que o do restante da cidade, $R \$ 502.888,00$, enquanto o preço médio dos lançamentos em toda a cidade é de $R \$ 225.186,60$.

TABELA 1 - PREÇO E CARACTERÍSTICAS DOS IMÓVEIS NO BELVEDERE

\begin{tabular}{l|l|l|l|l}
\hline Preço médio & Área média & Idade média & $\begin{array}{c}\mathrm{N}^{\circ} \text { de quartos } \\
\text { (média) }\end{array}$ & $\begin{array}{c}\mathrm{N}^{\circ} \text { de vagas } \\
\text { (média) }\end{array}$ \\
\hline $\mathrm{R} \$$ \\
$502.888,34$
\end{tabular}

FONTE: CMI (2004) citado por HILGERT et al. (2004)

Quanto à renda dos moradores do Belvedere, Hilgert et al (2004) apresenta as tabelas 2 e 3 :

TABELA 2 - RENDA (US\$) POR LOCALIZAÇÃO EM BELO HORIZONTE

\begin{tabular}{c|c}
\hline \multicolumn{2}{c}{ Localidade Renda média mensal das famílias (US\$) } \\
\hline Belvedere & $3.994,46$ \\
Regional Centro-sul & $1.511,32$ \\
Belo Horizonte & 509,18 \\
\hline
\end{tabular}

FONTE: IQVU/PBH 1996 citado por HILGERT et al .(2004) 
TABELA 3 - \% DE FAMÍLIAS COM RENDA SUPERIOR A 20 SALÁRIOS MÍNIMOS POR LOCALIZAÇÃO

\% famílias com renda superior a 20 salários mínimos por localidade

\begin{tabular}{c|c} 
Belvedere & 71 \\
Belo Horizonte & 9 \\
\hline
\end{tabular}

FONTE: IBGE/CENSO 2000 citado por HILGERT et al. (2004)

Quanto aos aspectos demográficos, Hilgert et al (2004), afirmam que em 1994, data pouco anterior a verticalização de fato, a população do bairro era de 3.017 pessoas. Em 2001, após a verticalização, a população passou para 4.733. O perfil do morador do Belvedere pode ser caracterizado como profissionais bem sucedidos em suas determinadas profissões, pois, o preço dos imóveis e o próprio custo elevado de vida é um grande fator de seleção da população. Em relação à faixa etária dos moradores do Belvedere, Hilgert et al (2004) apresentam a seguinte tabela:

TABELA 4 - CARACTERÍSTICAS DEMOGRÁFICAS DO BELVEDERE E BELO HORIZONTE

\begin{tabular}{lcc}
\hline Categoria & Belvedere & Belo Horizonte \\
\hline Crianças: 0-14 anos. & $16 \%$ & $20 \%$ \\
Jovens: $15-29$ anos. & $32 \%$ & $29 \%$ \\
Adulto jovem: $30-54$ anos. & $35 \%$ & $34 \%$ \\
Adulto maduro: 55-64 anos & $14 \%$ & $6 \%$ \\
Idosos: 65 anos em diante & $5 \%$ & $6 \%$
\end{tabular}

FONTE: IBGE CENSO 2000 citado por HILGERT et al. (2004)

A figura 2 demonstra que o bairro se localiza próximo ao centro econômico da cidade, sendo delimitado ao norte por alguns dos bairros mais ricos da capital mineira: Sion e Mangabeiras. Ao sudeste faz fronteira com a escarpa leste da Serra do Curral e politicamente com o município de Nova Lima. Contraditoriamente, ao oeste, é delimitado por alguns bairros com a presença de aglomerados de população de baixa renda: Santa Lucia e São bento. 


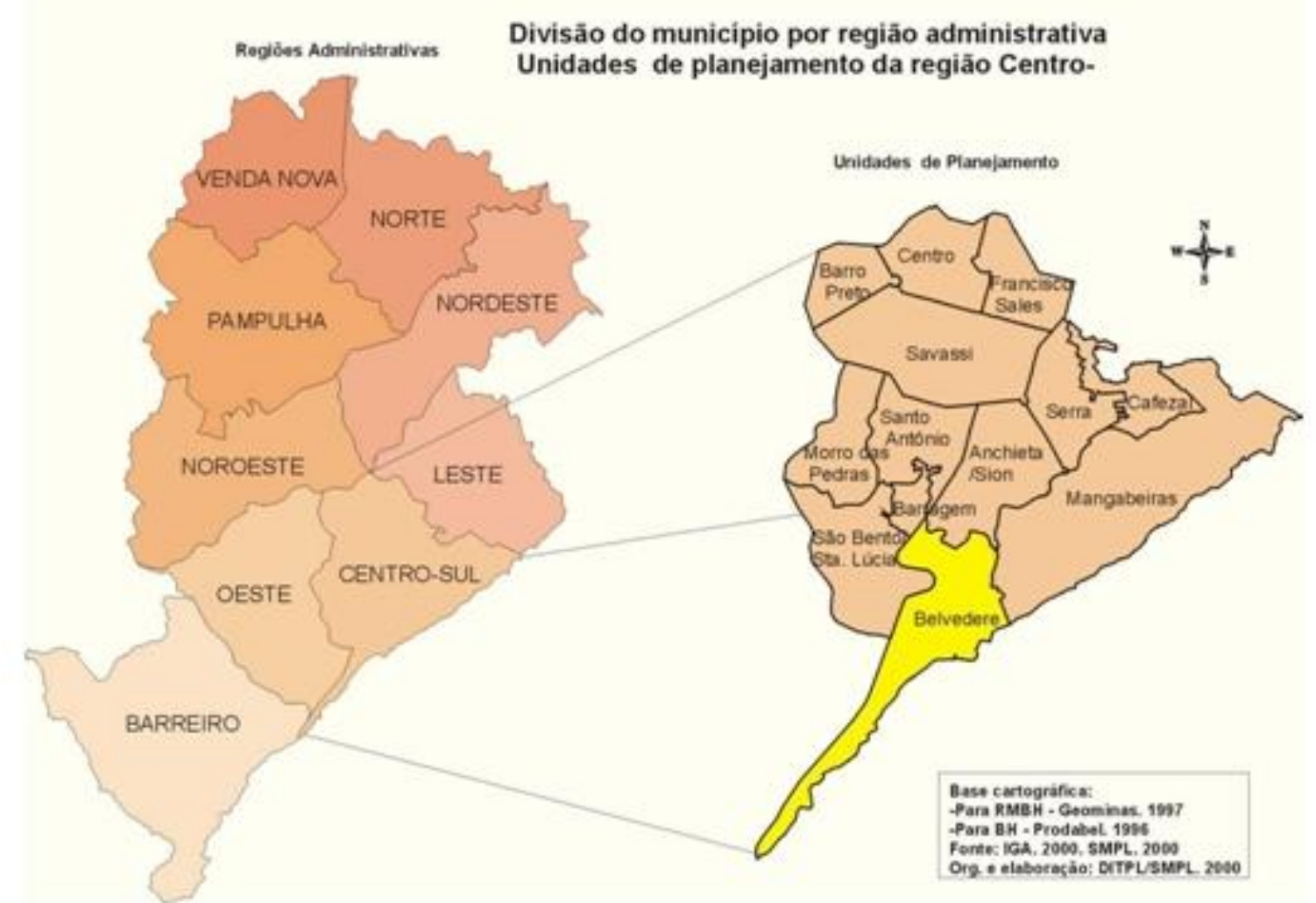

FIGURA 2 - DIVISÃO DO MUNICÍPIO POR REGIÃO ADMINISTRATIVA UNIDADES DE PLANEJAMENTO DA REGIÃO CENTRO SUL.

FONTE: IGA (2000), SMPL (2000). ORG. E ELABORAÇÃO DETPL/SMPL (2000)

Por meio dos mapas, é possível perceber o alto nível sócio-econômico do Belvedere, em relação aos demais bairros de Belo Horizonte. Porém, o abrupto processo de verticalização do Belvedere III, que se desenvolveu a partir do ano 2000, é um elemento que alterou a relação espaço-temporal dentro do bairro, pois, estabeleceu diferentes dinâmicas entre as partes do bairro, já que, as taxas de crescimento do Belvedere I e II se mantiveram mais estáveis comparadas às taxas do Belvedere III, após o ano 2000. Isso poderá ser melhor apreendido mais adiante quando forem delimitadas as geofácies que compõem a paisagem do Bairro.

\subsection{A TEMPORALIDADE DA PAISAGEM E CONFLITOS SOCIOAMBIENTAIS}


O bairro Belvedere, no início da construção de Belo Horizonte, era uma grande fazenda chamada Capão Grande. Hoje, é marcado pela ação antrópica: ocupação urbana, mineração, retirada da vegetação original, corte nas encostas, impermeabilização de grande parte do solo e pressão sobre área de solos filíticos, possibilitada por novas (e caras) tecnologias de construção civil. Apesar de toda pressão sobre esse compartimento da paisagem da capital, a área continua sendo uma paisagem simbólica da cidade de Belo Horizonte e, também, uma área de grande importância ambiental. Porém, o mapa de vulnerabilidade ambiental desenvolvido por Kux et al. (2007, p. 578), considerando dados de riscos geológicos-geotécnicos para o Belvedere (FIGURA 3), revela que existem áreas dentro do bairro que correm risco de escorregamentos de encostas. São áreas que podem potencialmente causar acidentes quando ocupadas ou alteradas pelo homem.

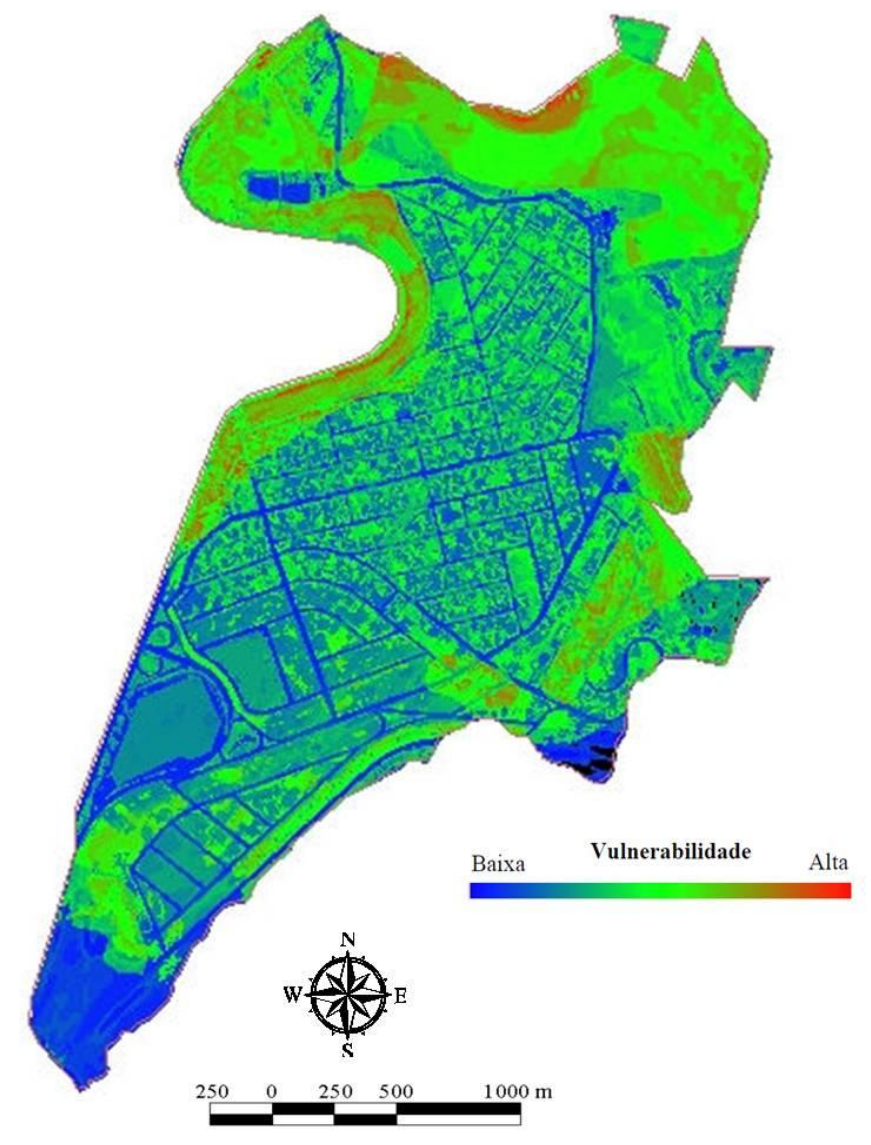

FIGURA 3 - MAPA DE VULNERABILIDADE AMBIENTAL À POPULAÇÃO E À PROPRIEDADE.

FONTE: KUX et al. (2007) 
A região onde hoje é o bairro Belvedere foi fracionada, na década de 1950, em um projeto de ampliação do setor sul de $\mathrm{BH}$. As terras que anteriormente pertenciam a fazenda Capão Grande foram divididas em lotes para atender à demanda, da elite belorizontina, por serem áreas de clima ameno e longe da agitação de áreas mais centrais. Logo, surgiu o bairro que até o fim dos anos oitenta permaneceu tranquilo, com suas mansões em estilo californiano. No início dos anos noventa, a lei que proibia a construção de prédios estava derrubada pelo prefeito do Sergio Ferrara, após considerável resistência de movimentos em defesa do meio ambiente e patrimônio de Belo Horizonte. A despeito da tensão inicial, hoje assistimos a uma divisão territorial nítida, no processo de ocupação do bairro: o território das tradicionais mansões, o território das suntuosas e modernas torres de alto luxo e um terceiro território de áreas de reserva para especulação imobiliária. Tudo isso permeado pela dinâmica comercial, os processos naturais de desgaste ou recomposição de recursos naturais, de futuras utilizações e de incertezas. Como todos os donos desses territórios pertencem às classes de padrão social elevado, os conflitos internos ao bairro são relativamente minimizados.

Nesse sentido, o tempo da paisagem do bairro Belvedere é uma espécie de "assinatura" que resultou das interações entre as temporalidades e as dinâmicas do geossistema e da cultural produzida pelas pessoas que habitam este espaço-território. A marca da natureza e do se humano, que atua sobre essa base natural, ao longo do tempo, estão em constante interação e isso é o que torna o Belvedere uma paisagem individualizável dentro de Belo Horizonte (Figura 4). A Serra do Curral atua como um símbolo e marca a feição do bairro que, por sua vez, também deixa sua marca na serra. Ao expectador fica a imagem de uma paisagem, construída pela "sociedade" da capital mineira, e que representa, incontestavelmente, as diferenças sociais, na qual essa sociedade está inserida. 
Transecto UFMG - Serra do Curral (Belvedere)

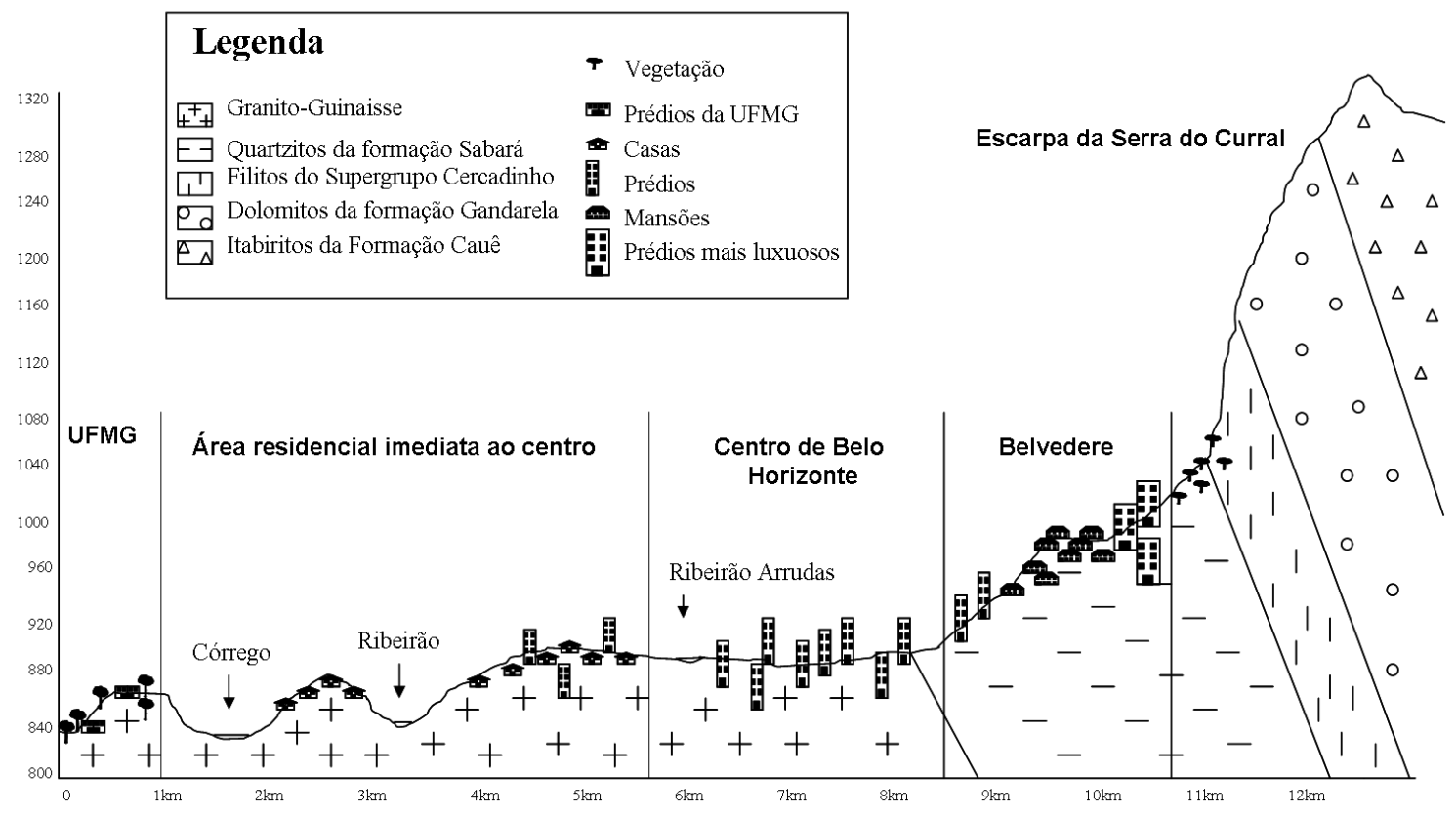

FIGURA 4: COMPARTIMENTAÇÃO DA PAISAGEM DO TRANSECTO UFMG BELVEDERE, EM BELO HORIZONTE

FONTE: CARTA TOPOGRÁFICA DE BELO HORIZONTE

Por outro lado, verifica-se a existência de áreas do belvedere que possuem diferentes dinâmicas espaço-temporais e, por meio da identificação dessas áreas, foram delimitadas as geofácies que compõem a paisagem do bairro.

\subsection{OS SISTEMAS NATURAIS, SOCIAIS E A HOMOGENEISAÇÃO DAS GEOFACIES}

Entre os problemas ambientais ocasionados pela rápida urbanização do Belvedere III está a destruição da vegetação e dos recursos hídricos do local. Os empreendimentos demandam aterros e terraplanagem que cada vez mais descaracterizam a paisagem do local. Esta ação acarreta ainda, o transporte de sedimentos para o sistema de drenagem pluvial local. A área próxima à Lagoa Seca, por ser considerada como Zona de Proteção Ambiental, em conformidade com a legislação urbanística, jamais poderia ter sido alvo de parcelamento, conforme pode ser verificado no artigo $16 \S \mathrm{VI}$, cap. III, da Lei 7.166/96, mas, além de receber a água pluvial oriunda do Belvedere III e do BH Shopping, teve 
sua área reduzida em virtude do zoneamento aplicado ao bairro. Também, a verticalização do bairro causou violenta obstrução à visualização da Serra do Curral e com a impermeabilização do solo causada pela edificação dos lotes contidos no Belvedere III ouve um comprometimento da manutenção da recarga dos aquíferos que abastecem a bacia hidrográfica do Córrego Cercadinho.

O desmatamento total de áreas verdes (campo cerrado) para construção das edificações e a expansão urbana ao longo da bacia do Córrego Cercadinho são bons exemplos de como a ocupação do Belvedere III, surge com diversas especificidades que o coloca na condição de um recorte espacial dentro da paisagem do bairro distinguível do seu entorno (Belvedere I e II), sendo o resultado de uma particular interferência da sociedade e sua temporalidade na dinâmica e na temporalidade do geossistema local.

A figura 6 mostra como a paisagem do Belvedere foi rapidamente alterada após a construção do Belvedere III, em que a quantidade de prédios aumentou significativamente em apenas seis anos. Comparada com a figura 5, que representa o Belvedere I e II, nota-se que a ocupação destes se manteve mais estável no mesmo período. Esta comparação permite a identificação de duas geofácies distintas dentro dos limites do Belvedere, pois possuem especificidades em relação a sua temporalidade e dinâmica.

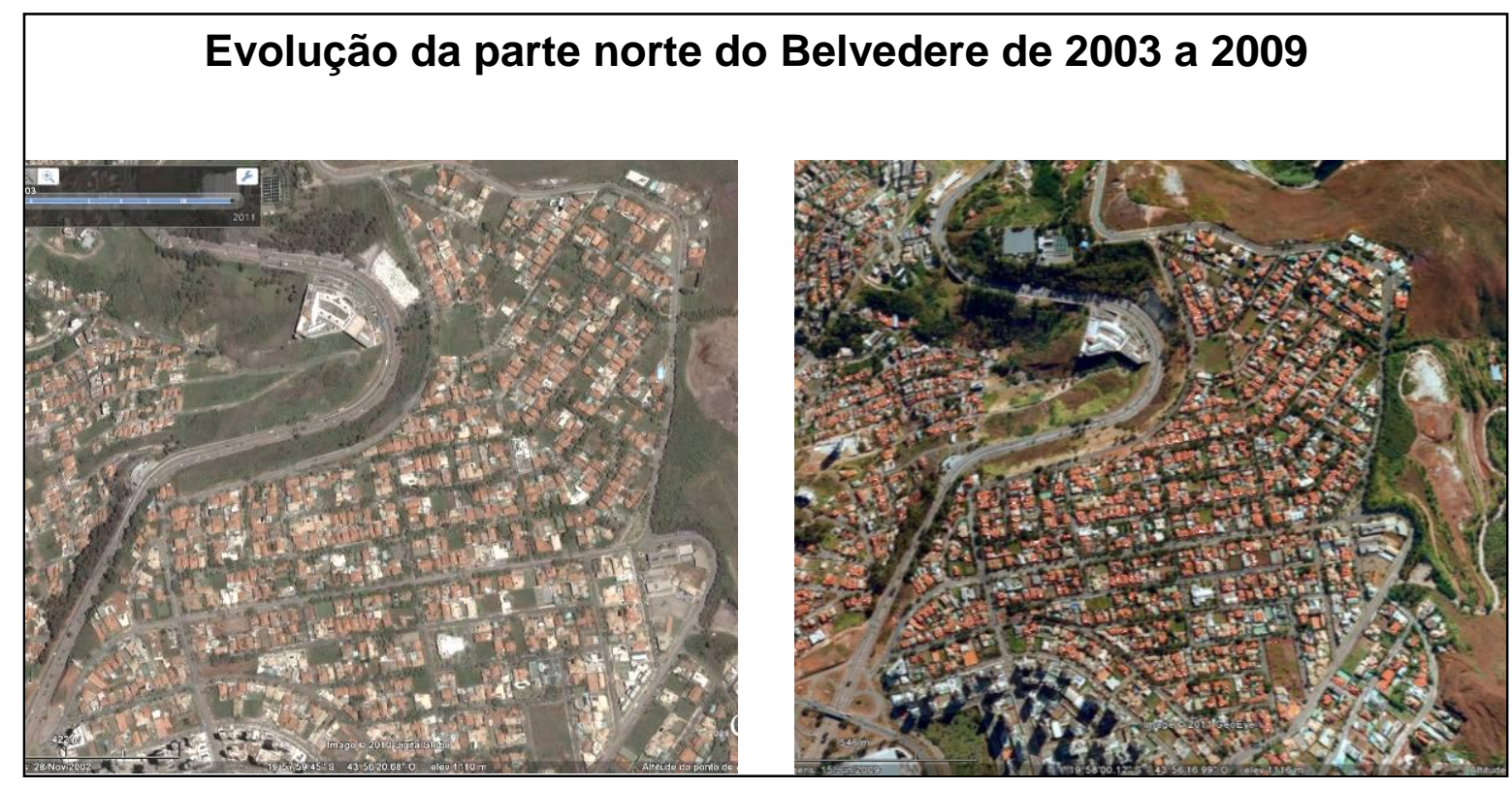

FIGURA 5 - EVOLUÇÃO DA PARTE NORTE DO BELVEDERE DE 2003 A 2009 FONTE: IMAGENS GOOGLE EARTH 


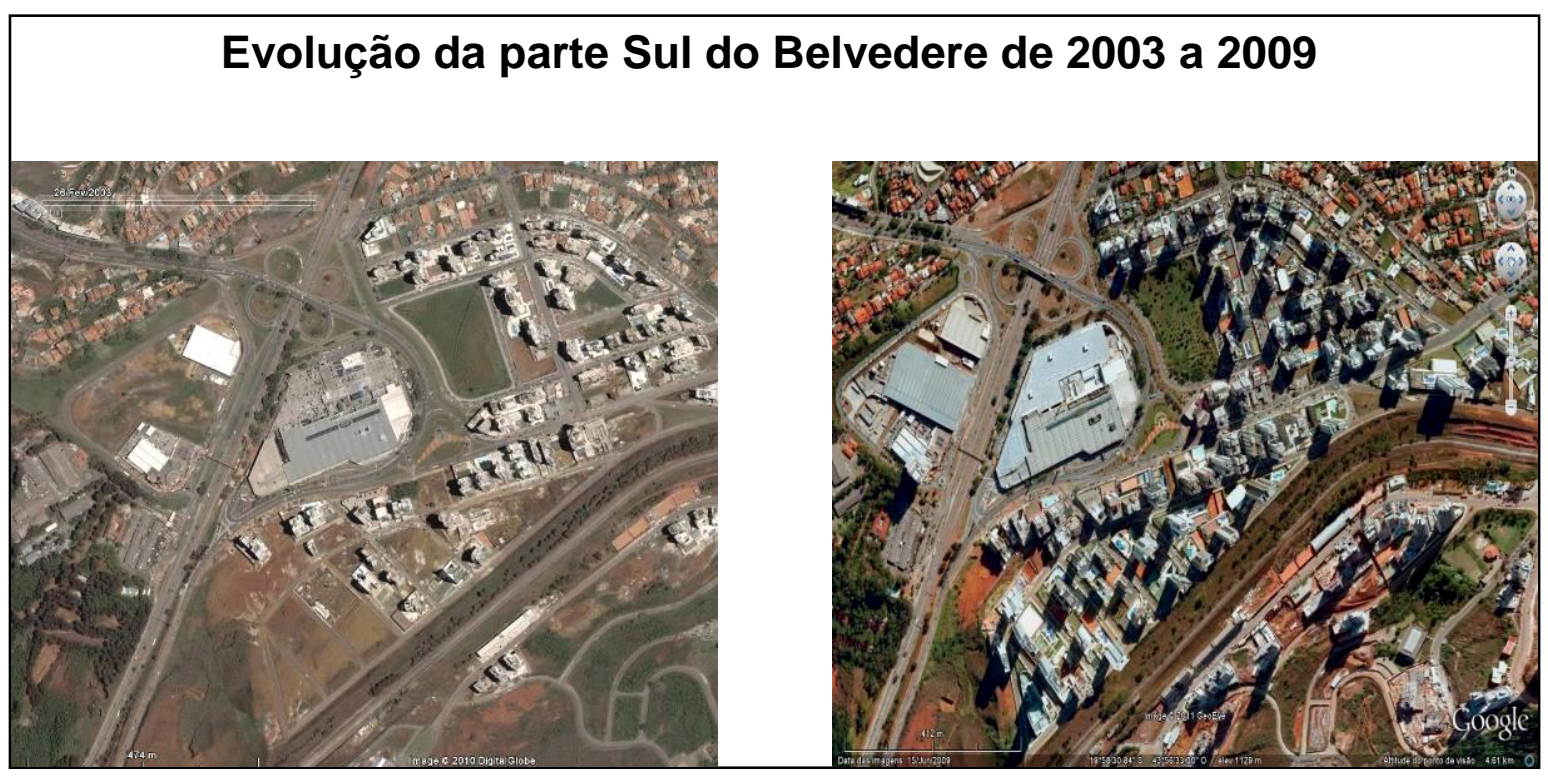

FIGURA 6 - EVOLUÇÃO DA PARTE SUL DO BELVEDERE DE 2003 A 2009 FONTE: IMAGENS GOOGLE EARTH

A paisagem do bairro Belvedere se mostra homogênea no tocante a sua caracterização socioeconômica e cultural, sendo no contexto da cidade de Belo Horizonte, marcada pelo luxo e pela valorização fundiária, assim como pela concentração de renda e por uma população já envelhecida. Contudo, é notório que existem padrões construtivos e porções muito diferenciadas dentro dessa paisagem que, no contexto da cidade é homogênea, mas quando analisada na escala do bairro apresenta três configurações muito distintas.

A figura 7 expressa a classificação das geofácies conforme as especificidades das geofácies identificadas. Nas extremidades do bairro, encontra-se áreas verdes caracterizadas como terrenos destinados à especulação imobiliária ou a preservação ambiental. Na porção norte, e ao sul da área verde, encontra-se o Belverede I e II com padrão urbanístico menos luxuoso em relação aos prédios do Belvedere III. O Belvedere I e II apresenta uma porção do bairro onde se destaca uma paisagem típica dos bairros ricos da cidade com presença de mansões e casas de luxo e é a porção "horizontalizada" do bairro. Por último, na porção sul, e ao norte da área verde, encontra-se o Belverede III caracterizado pela presença dos prédios e construções mais modernas, sendo 
esta, a porção verticalizada do bairro, onde está localizada a população mais recente do bairro.

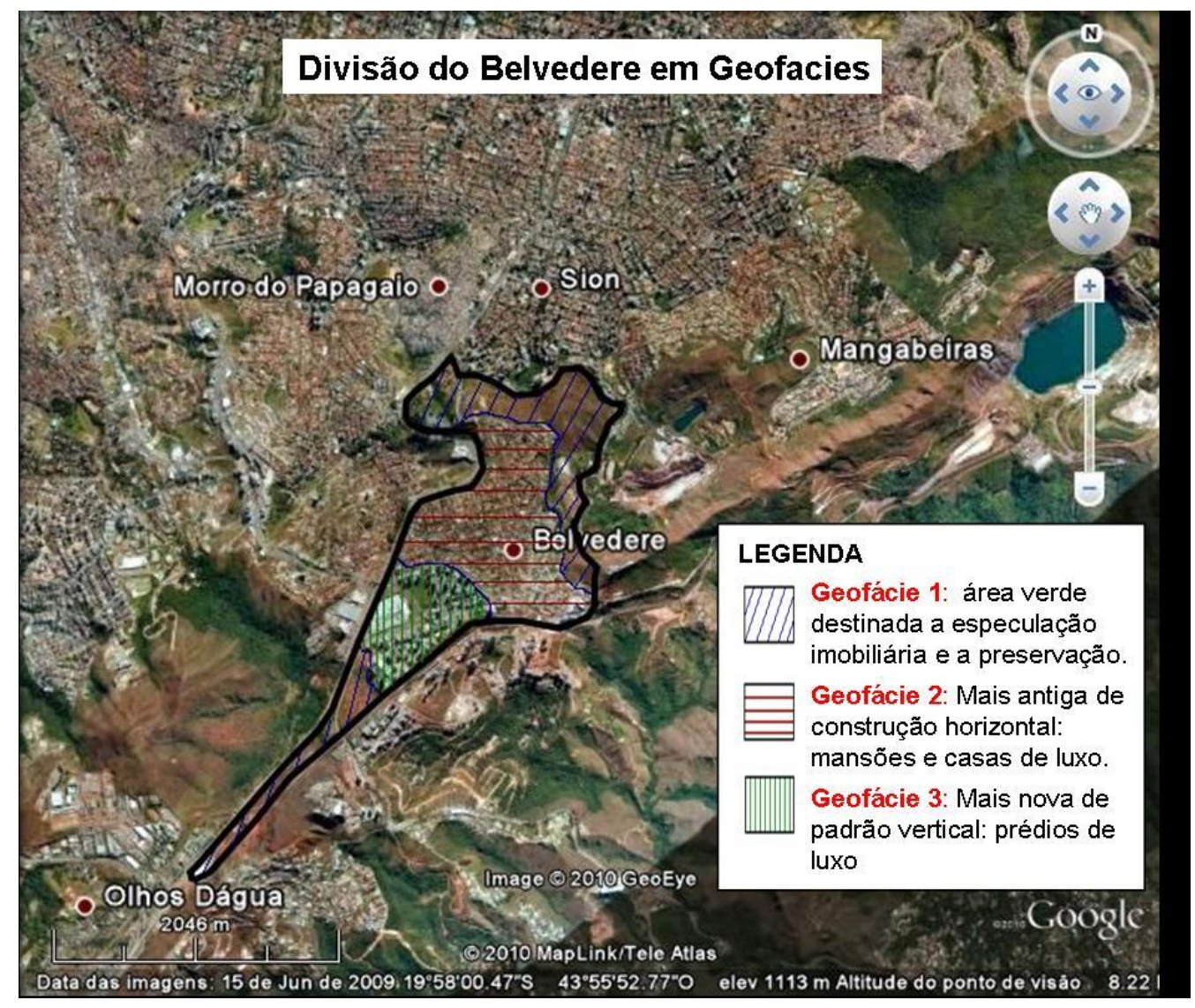

FIGURA 7 - DIVISÃO DO BELVEDERE EM GEOFÁCIES

FONTE: IMAGEM GOOGLE EARTH

\section{CONSIDERAÇÕES FINAIS}

Percebemos pelo estudo de caso dessa pequena porção do território da cidade de Belo Horizonte, o Belvedere, que a produção do espaço se constituiu de maneira fragmentada, formando uma paisagem conflituosa, excludente e socioespacialmente dividida, em que os mais ricos localizam-se de um lado e pobres do outro. A partir da Metodologia do GTP proposta por Bertrand (2007), consegue-se identificar as diferentes territorialidades e temporalidades que dão ao bairro Belvedere a condição de paisagem que se distingue do recorte paisagístico maior, a cidade de Belo Horizonte. Nesse sentido, o Belvedere emerge como um compartimento da paisagem de Belo Horizonte, por apresentar 
diferenças marcantes em relação ao seu entorno. Por meio desse estudo foi possível também identificar, dentro dos limites do próprio Belvedere, três geofácies, que mesmo estando contidas no mesmo compartimento da paisagem (o Belvedere), possuem dinâmicas e temporalidades distintas. Essas diferenças entre as geofácies do bairro exigem que o poder público adote um olhar não homogêneo ao pensar em políticas públicas para a área e considere as especificidades existentes entre esses compartimentos dessa paisagem.

A partir das informações analisadas, a valorização da área sinaliza para um acirramento da disputa territorial, pois a área destinada à preservação ambiental se torna a única possibilidade de crescimento urbano dentro do Belvedere. Também, verifica-se uma concentração da população mais tradicional do bairro na geofácie 2, o que exige uma política mais especifica para essa população tradicional o que pode gerar conflitos como, por exemplo, pela apropriação noturna no bairro, visto que a população mais jovem se concentra na geofácie 3 . De qualquer forma, as possibilidades de crescimento do Belvedere se esgotam à medida que a população cresce e satura o bairro. A valorização fundiária acompanhou todo o processo, levando a um maior interesse de investimento das construtoras, que estão cada vez mais presentes e atuando na verticalização do bairro.

A construção do Belvedere I II e, principalmente, o III causou sérios e irreversíveis danos ao meio ambiente e, por isso, a sociedade e o poder público não podem perder de vista a questão ambiental. Nessa área, a dinâmica do geossistema foi significativamente alterada pela dinâmica do território e a paisagem que emerge dessa interação denota os problemas advindos da forma fragmentada de se pensar e conceber a produção do espaço, em que o lucro e a ganância sempre falam mais alto. Dessa forma, o GTP aparece como uma alternativa metodológica para os geógrafos e demais pesquisadores capaz de reduzir significativamente os dualismos existentes na forma de agir e pensar o meio ambiente e a complexa relação sociedade-natureza.

Atualmente, o poder público conseguiu embargar a expansão do Belvedere III, pois, considerou que o empreendimento desrespeitou a legislação existente e tem causado problemas irreversíveis ao meio ambiente da região. Mas, não há quem possa garantir que esse embargo dure para sempre, pois, como verificado 
na implantação do bairro, no Brasil sempre é possível encontrar um jeito de burlar as leis. Nesse sentido, o que fica de mais importante desse estudo é certeza que a paisagem é o resultado de uma constante construção e reconstrução e esse processo continuo e está submetido à constantes conflitos que perpassam as esferas do geossistema e do território.

\section{REFERÊNCIAS}

BERTRAND, G. Paisagem e geografia física global: esboço metodológico. Caderno de Ciências da Terra, n. 13, p. 1-27, 1971.

BERTRAND, G.; BERTRAND, C. Uma geografia transversal e de travessias: o meio ambiente através dos territórios e das temporalidades. Maringá: Massoni, 2007.

DIAS, J. B. A dimensão dos sistemas naturais na (re) produção dos sistemas agrícolas da agricultura familiar: análise da paisagem de três comunidades rurais na Região Metropolitana de Curitiba (em São José dos Pinhais, Mandirituba e Tijucas do Sul). Tese (Doutorado) - Universidade Federal do Paraná. Curitiba, 2006. p. 334.

HAESBAERT, R. Concepções de território para entender a desterritorialização. In: SANTOS, M.; Becker, B. Território, territórios: ensaios sobre o ordenamento territorial. Rio de Janeiro: Lamparina Editora, 2002. p. 17-39.

HILGERT, N. A.; KLUG, L.B.; PAIXÃO, L. A. A "criação" do Bairro Belvedere III em Belo Horizonte: Inovação Espacial, Valorização Imobiliária e Instrumentos Urbanísticos. In PAULA, J.A. de et alli, et eds., Anais do XI Seminário sobre a Economia Mineira (Proceedings of the 11th Seminar on the Economy of Minas Gerais), Cedeplar, UFMG, 2004. Disponível em: http://econpapers.repec.org/RePEc:cdp:diam04:200469. Acessado em: 20 de novembro de 2010.

KUX, H. J. H.; ARAUJO, E. H. G.; DUPONT, H. S. J. B. Imagens de alta resolução do satélite Quickbird e técnicas de SIG para a análise de problemas geológicogeotécnicos em áreas urbanas: estudo de caso Belo Horizonte (MG). Anais XIII Simpósio Brasileiro de Sensoriamento Remoto, Florianópolis, Brasil, 21-26 abril 2007, INPE, p. 573-580.

PREFEITURA DE BELO HORIZONTE. Plano Diretor: Lei n. 7.165, de agosto de 1996; Parcelamento, ocupação e uso do solo urbano, Lei n. 7.166 de 1996 . Belo Horizonte: Prefeitura, 1996. 
RODRIGUES, M. G. Zona de Fronteira: a expansão urbana recente na zona sul de Belo Horizonte. Trabalho apresentado no I Congresso Brasileiro de Direito Urbanístico, Belo Horizonte, 2000. mimeo.

ROUGERIE, G. e BEROUTCHACHVILI, N.L. Géosystèmes et paysages. Bilan et métodes. Paris: Armand Colin, 1991. 320 p.

SANTOS, M. O retorno do território. In: Território: globalização e fragmentação. São Paulo, Hucitec/Anpur, 1994 (15-20).

Por uma outra Globalização. 6 ed. Rio de Janeiro: Record, 2001.

SOCHAVA, V. B. Introdução à Teoria do Geossistema. Novasibéria: Nauka. 1978. $320 \mathrm{p}$.

(Recebido em 04.08.2011. Aceito em 21.11.2011) 